\title{
TRANSEXUALIDADE E EDUCAÇÃO MÉDICA: UM ESTUDO ANALÍTICO ${ }^{1}$
}

\section{TRANSEXUALITY AND MEDICAL EDUCATION: AN ANALYTICAL STUDY}

\author{
TRANSEXUALIDAD Y EDUCACIÓN MÉDICA: UN ESTUDIO ANALÍTICO
}

Carlos Alberto Severo Garcia-Jr

Universidade Federal de Santa Catarina, Brasil http://orcid.org/0000-0003-3367-4151 carlosgarciajunior@hotmail.com

Liana Cristina Dalla Vecchia Pereira Universidade Federal de Santa Catarina, Brasil https://orcid.org/0000-0002-4200-2464 lianadvp@gmail.com

Amanada Steil

Universidade Federal de São Paulo, Brasil https://orcid.org/0000-0002-0417-2921 amanda.steil@hotmail.com

Jair Josué Laurentino dos Reis Universidade do Vale do Itajaí, Brasil https://orcid.org/0000-0003-3824-8135 jairjosuer@hotmail.com

Júlia de Sá Liston Universidade do Vale do Itajaí, Brasil https://orcid.org/0000-0002-1262-3470 julia.10sali@gmail.com

Mariana Andréa de Moura Henicka Universidade do Vale do Itajaí, Brasil https://orcid.org/0000-0002-2683-2708 marihenicka@gmail.com

Recebido:29/08/2020 Revisado: 23/09/2020 Aceito:05/10/2020 Publicado: 01/11/2020

Resumo: A educação médica requer adaptações curriculares de acordo com as necessidades de saúde articuladas às questões sociais da população. Para tanto, este estudo teve como objetivo analisar como o tema da transexualidade é abordado no curso de medicina de uma universidade de Santa Catarina, região sul do Brasil. Trata-se de uma pesquisa qualitativa descritiva com dois procedimentos metodológicos: análise documental dos planos de ensino do curso de medicina e grupos focais com estudantes de medicina. A análise de conteúdo foi utilizada enfocando os termos: transexualidade, identidade sexual, sexualidade, diversidade, gênero, disfunções psicossexuais, transexualidade e transgênero. Embora o tema esteja presente em alguns planos de

${ }^{1}$ O presente trabalho foi realizado com apoio da Coordenação de Aperfeiçoamento de Pessoal de Nível Superior - Brasil (CAPES) - Código de Financiamento 001.

e-ISSN:2172-7910

Doi:10.25267/Hachetetepe.2020.i21.6

Universidad de Cádiz 
ensino, sua inserção ainda é incipiente e limitada no processo educacional com ênfase na aprendizagem de habilidades para "usar uma linguagem neutra". As interlocuções nos grupos focais demonstram a importância do compromisso ético para a atuação profissional diante das demandas das pessoas transexuais. No entanto, os/as estudantes identificam práticas cotidianas ligadas a valores morais. Conclui-se que não há uma determinação formal da questão transexual no currículo médico desta universidade, evidenciando a necessidade de qualificar a formação para uma atuação ético-política.

Palavras-chave: Educação universitária; Medicina; Sexualidade; Transexualidade.

Abstract: Medical education requires curricular adaptations according to health needs articulated to social issues populations. Therefore, this study aimed to analyse how the topic of transsexuality is approached in the medical course of a university in Santa Catarina, South region of Brazil. This is a descriptive qualitative investigation with two methodological procedures: analysis of medicine teaching plans and focus groups with medical students. Content analysis was used focusing on the terms: transsexuality, sexual identity, sexuality, diversity, gender, psycho-sexual dysfunctions, transsexuality and transgender. The topic is present in some curricula teaching plans, but it is still incipient and limited in the educational process with an emphasis on learning skills to "use neutral language". The discussions in the focus groups demonstrate the importance of ethical commitment to professional performance facing the demands of transsexual people. However, students identify everyday practices linked to moral values. It is concluded that there is no formal determination of transsexuality topic in the medical curriculum of this university, revealing the need to qualify the training for an ethical-political performance.

Keywords: University education; Medical sciences; Sexuality; Transsexuality.

Resumen: La educación médica requiere adaptaciones curriculares según las necesidades de salud articuladas a las cuestiones sociales de las poblaciones. Para tal, este estudio tuvo como objetivo analizar cómo se aborda el tema de la transexualidad en el curso de medicina de una universidad de Santa Catarina, región sur de Brasil. Se trata de una investigación cualitativa descriptiva con dos procedimientos metodológicos: análisis documental de los planes de enseñanza del curso de medicina y grupos focales con estudiantes de medicina. Se utilizó el análisis de contenido enfocándose en los términos: transexualidad, identidad sexual, sexualidad, diversidad, género, disfunciones psicosexuales, transexualidad y transgénero. El tema está presente en algunos planes de enseñanza, pero su inserción aún es incipiente y limitada en el proceso educativo con énfasis en el aprendizaje de habilidades para "usar un lenguaje neutral". Las interlocuciones en los grupos focales demuestran la importancia del compromiso ético para el desempeño profesional frente a las demandas de las personas transexuales. Sin embargo, los/las estudiantes identifican prácticas cotidianas vinculadas a los valores morales. Se concluye que no hay una determinación formal del tema transexualidad en el currículo médico de esta universidad, evidenciando la necesidad de calificar la formación para un desempeño ético-político.

Palabras claves: Educación universitaria; Medicina; Sexualidad; Transexualidad.

Como citar este artigo: Severo, C.A., Dalla, L. C., Steil, A., Laurentino, J.J. De Sá, J. y de Moura, M. A. (2020). Transexualidade e educação médica: um estudo analítico. Hachetetepé. Revista científica en Educación y Comunicación, (21), 56-69. https://doi.org/10.25267/Hachetetepe.2020.i21.6

\section{INTRODUÇÃO}

Com a expansão do campo científico e a consequente produção de novos conhecimentos, é notável a rapidez com a qual os saberes se tornam obsoletos. Essa movimentação ágil do conhecimento gera a necessidade de criar hábitos e métodos que

e-ISSN:2172-7910

Doi:10.25267/Hachetetepe.2020.i21.6

Universidad de Cádiz 
valorizem o auto aprendizado, a inquietação permanente e a abordagem crítica daquilo que é aprendido (Campos y Belisário, 2001). Para isso, a educação profissional precisa transmitir valores e atitudes, além do conhecimento. $\mathrm{Na}$ educação em saúde essa transmissão ocorre, principalmente, na transversalidade das "humanidades", ou seja, nas disciplinas que visam à formação de uma visão holística do ser humano (Ristow, 2007). Entretanto, há evidências de que a medicina ainda não está aberta à mudança de paradigma necessária, pois a formação médica ainda se depara com a ausência ou a marginalidade de disciplinas de caráter humanístico nas matrizes curriculares (Ribeiro y Amaral, 2008). O desafio se amplifica ao considerar o tema da transexualidade no universo acadêmico somado à cultura heteronormativa que inferioriza e desqualifica o que escapa aos padrões heterossexuais e cisgênero (Santos y Cruz, 2014).

Em consulta às bases de dados Lilacs, PubMed e Scielo utilizando os descritores "transexualidade/transexuality" combinado à "educação médica/medical education", encontramos poucos artigos publicados até agosto de 2020 sobre transexualidade na graduação de medicina dentre os resumos disponíveis. Encontramos 12 artigos na Lilacs (Literatura Latino-Americana e do Caribe em Ciências da Saúde), dos quais apenas 2 estudos se referem à graduação de medicina. Estes elucidam a pouca abordagem do tema na formação médica (Ling-Fang y Hsing-Chen, 2015) e a inadequação do conhecimento às necessidades das pessoas transexuais (Rondahl, 2009). No PubMed encontramos 30 artigos, dos quais 6 se relacionam à educação médica na graduação, sendo que 2 se repetem da Lilacs, As demais pesquisas evidenciam que estudantes com maior exposição ao atendimento de pessoas LGBTI+ (lésbicas, gays, bissexuais, transexuais, intersexo) têm maior conhecimento das suas questões de saúde e realizam uma abordagem mais compreensiva (Sanchez et al., 2006). Outro estudo elucida que o aprendizado sobre a saúde de pessoas transexuais ainda é menos retratado do que a saúde de pessoas LGB (Liang et al., 2017). Nas escolas de medicina dos Estados Unidos e Canadá, o tempo médio relatado dedicado a tópicos relacionados à saúde LGBT em 2009-2010 foi pequeno, sendo que a quantidade, o conteúdo coberto e a qualidade percebida da instrução variaram substancialmente (Obedin-Maliver et al., 2011). Quanto ao corpo docente, professores que percebem mais barreiras para o ensino da saúde LGBTI+ dedicaram menos tempo a esses tópicos (Tamas et al., 2010). Não encontramos nenhum artigo sobre o ensino de temas relacionados à transexualidade na graduação médica no Brasil, o que se confirma na busca realizada na Scientific Electronic Library Online (SciELO). Essa lacuna evidencia a relevância da realização de pesquisas nessa área.

$\mathrm{Na}$ busca por modelos tradicionais e pela adequação à ordem, a medicina se apropria da transexualidade como um problema médico (Leite y Santos, 2016). Ao considerar as pessoas como pertencentes à dicotomia feminino ou masculino, a educação médica desconsidera as múltiplas possibilidades de vivenciar as expressões do gênero e da sexualidade, limitando os modos de existência. Para minimizar as consequências dessa perspectiva reducionista que ainda norteia a avaliação, o diagnóstico e a intervenção médica, faz-se necessário a reorientação do ensino médico para que as pessoas não sejam discriminadas e tenham tratamentos adequados (ONU, 2012).

Nesse sentido, a educação médica requer adaptações curriculares de acordo com as necessidades de saúde articuladas às questões sociais das populações. Para tanto, este estudo teve como objetivo analisar como o tema da transexualidade é abordado no curso de medicina de uma universidade de Santa Catarina, região sul do Brasil. Busca-se dar visibilidade à temática para contribuir para uma formação ético-política que contemple a

e-ISSN:2172-7910

Doi:10.25267/Hachetetepe.2020.i21.6

Universidad de Cádiz 
diversidade dos modos de viver e existir. Ao considerar a importância dos saberes e das práticas médicas na sociedade em que vivemos, além da lacuna de pesquisas sobre a transexualidade na educação médica, torna-se fundamental o estudo da temática em questão do processo de formação médica no contexto brasileiro.

\section{METODOLOGIA}

Trata-se de um estudo de abordagem qualitativa e nível descritivo. Para Minayo (2014), a pesquisa qualitativa se propõe a estudar as experiências, percepções, representações e interpretações em relação aos modos de viver, sentir e pensar. Essa perspectiva valoriza a subjetividade e a singularidade das pessoas na relação com o meio e momento histórico em que vivem, buscando interpretar e construir relatos pluralizados, individual e coletivo, simultaneamente.

Este estudo foi desenvolvido em uma instituição privada de ensino superior localizada em cidade litorânea de médio porte com a segunda maior renda per capita de Santa Catarina. O estado está na região sul do Brasil, contando com cursos de medicina em 2 universidades públicas federais, 1 comunitária e em 7 instituições privadas. A escolha da universidade privada deste estudo se justifica por se constituir como referência na formação de medicina na região, com a implementação do curso em 1998, tendo formado 29 turmas até 2018, ano em que a pesquisa foi realizada. Semelhante a outros estados, há maior oferta de vagas para medicina em instituições privadas do que em universidades públicas, aspecto que limita o acesso a pessoas que dispõem de condições socioeconômicas para financiar os altos custos do curso.

$\mathrm{Na}$ universidade participante do estudo, a formação médica possui carga horária de 8.295 horas, distribuídas em 12 semestres, sendo os 7 primeiros destinados aos ciclos básico e pré-clínico e os 5 últimos ao ciclo clínico prático ou Internato Médico. A matriz curricular possui um enfoque predominantemente clínico com apenas uma disciplina de caráter humanístico em cada um dos sete primeiros semestres do curso e nenhuma nos últimos anos. O corpo docente do curso era composto por 153 professores até 2018, dentre os quais, 73 especialistas, 53 mestres/as e 27 doutores/as.

A pesquisa foi realizada em 2018 utilizando dois procedimentos metodológicos para a coleta de dados: análise dos planos de ensino das disciplinas do curso de medicina e realização de dois grupos focais com estudantes de medicina. A análise documental parte da busca dos termos: transexualidade, identidade sexual, sexualidade, diversidade, gênero, disfunções psicossexuais, transexualismo e transgênero. $O$ grupo focal se caracteriza como uma entrevista ou conversa em grupos pequenos e homogêneos que favorecem a interação entre participantes em ambiente não diretivo seja para gerar consenso, seja para explicitar divergências (Minayo, 2014).

Foram realizados dois grupos focais em salas reservadas na própria universidade com a duração de uma hora e quarenta minutos cada encontro, orientados por questõesnorteadoras para suscitar o diálogo. Os grupos foram coordenados por um professor e pesquisador na área da saúde, com formação em psicologia doutorado em ciências humanas, junto a três estudantes de medicina que integravam o projeto de iniciação científica. Estes foram supervisionados pelo primeiro e participaram do curso preparatório para a pesquisa de campo. Os diálogos foram gravados e transcritos mediante autorização das/os participantes. A análise foi realizada com base nos princípios da análise de conteúdo temática com atenção ao significado contextual (Bardin, 2011). Os resultados são apresentados de modo descritivo e por meio de recortes dos planos de 


\section{Hachetetepé. Revista científica de Educación y Comunicación}

nº21, 56-69, 2020

ensino e das falas dos grupos focais. Todas as narrativas dos grupos focais foram analisadas, porém escolhemos os excertos que suscitaram inquietações pertinentes no coletivo, ou seja, relatos que reverberaram nas/os demais despertando o interesse em compartilhar suas experiências e perspectivas.

A população alvo dos grupos focais corresponde a estudantes entre o $3^{\circ}$ e $7^{\circ}$ semestres do curso de medicina em 2018. Optou-se por não incluir estudantes do $1^{\circ} \mathrm{e} 2^{\circ}$ semestres devido à inserção inicial no curso, e discentes a partir do $8^{\circ}$ semestre, período em que estão no Internato Médico com ampla carga de estágios fora da universidade, o que dificultaria a participação. A seleção ocorreu por meio de convite e manifestação do interesse em participar, constituindo uma amostra intencional. A preferência pelos semestres intermediários se justifica pela imersão nos conhecimentos teóricos e vivências nos cenários de prática. Cada grupo focal contou com a participação de seis estudantes, totalizando doze participantes.

O presente estudo foi aprovado pelo Comitê de Ética em Pesquisa número CAAE 84981818.8.0000.0120, conforme o parecer 2.577.514 disponível em 03/04/2018. Foi utilizado o Termo de Consentimento Livre e Esclarecido com todos/as participantes. O projeto contou com fonte de financiamento do Programa de Bolsas Universitárias da Constituição do Estado de Santa Catarina (UNIEDU) no âmbito do Artigo 170. Os/as autores/as não possuem nenhum conflito de interesse.

\section{RESULTADOS E DISCUSSÃO}

Para melhor detalhar os dados coletados, apresentamos, na Tabela 1, a presença ou ausência das palavras-chave pesquisadas nos planos de ensino das disciplinas do curso de medicina em casa semestre, além da frequência e modo como comparecem no material.

\section{Tabela 1}

Evidência dos Termos nos Planos de Ensino do Curso de Medicina

\begin{tabular}{llcc}
\hline Semestre & Disciplina(s) & Palavras-chave & Forma de abordagem \\
\hline $1^{\text {o }}$ & $\begin{array}{l}\text { Humanidades } \\
\text { Médicas }\end{array}$ & $\begin{array}{c}\text { Sexualidade (1) } \\
\text { Diversidade (2) } \\
\text { Gênero (2) }\end{array}$ & $\begin{array}{c}\text { Conteúdo programático } \\
\text { e cronograma }\end{array}$ \\
$2^{\text {o }}$ & Saúde Coletiva & Diversidade (1) & Conteúdo programático \\
$2^{\text {o }}$ & Semiologia & Diversidade (3) & Conteúdo programático e \\
& Atenção Básica & Diversidação
\end{tabular}




\section{Hachetetepé. Revista científica de Educación y Comunicación}

nº21, 56-69, 2020

Transexualidade (1)

$\begin{array}{clcc}4^{\circ} & \text { Pediatria } & \text { Sexualidade (1) } & \text { Conteúdo programático } \\ 4^{\circ} & \text { Semiologia } & \text { Diversidade (2) } & \text { Conteúdo programático } \\ 5^{\circ} & \begin{array}{l}\text { Humanidades } \\ \text { Médicas }\end{array} & \text { Gênero (2) } & \text { Conteúdo programático } \\ 5^{\circ} & \text { Medicina Legal } & \text { Sexual (4) } & \begin{array}{c}\text { Ementa e conteúdo } \\ \text { programático }\end{array}\end{array}$

$6^{\circ} \quad$ Não foi observada a ocorrência dos termos pesquisados em nenhuma das disciplinas.

$\begin{array}{clcc}7^{\circ} & \text { Clínica Médica } & \text { Sexual (2) } & \text { Conteúdo programático } \\ 7^{\circ} & \text { Saúde Mental } & \text { Sexual (1) } & \text { Conteúdo programático } \\ & & \begin{array}{c}\text { Diversidade (1) e } \\ \text { Gênero (1) }\end{array} & \\ 8^{\circ} & \text { Internato de Saúde } & \text { Sexual (1) e } & \text { Outros critérios de avaliação } \\ & \text { Mental } & \text { Gênero (1) } & \end{array}$

$9^{\circ} \quad$ Não foi observada a ocorrência dos termos pesquisados em nenhuma das disciplinas.

$10^{\circ} \quad$ Não foi observada a ocorrência dos termos pesquisados em nenhuma das disciplinas.

$11^{\circ} \quad$ Não foi observada a ocorrência dos termos pesquisados em nenhuma das disciplinas.

Não foi observada a ocorrência dos termos pesquisados em nenhuma das disciplinas.

Fonte: Planos de Ensino do Curso de Medicina da Universidade-Participante no ano de 2018

A análise dos planos de ensino constata que alguns dos temas relacionados à transexualidade comparecem em treze disciplinas do curso, com significativa diferença entre os semestres dos ciclos básico e pré-clínico para o internato, pois os termos não estão presentes nos documentos dos últimos anos. Os trechos dos documentos os quais aprofundamos a análise referem-se, principalmente, às disciplinas do $4^{\circ}, 5^{\circ}, 7^{\circ}$ e $8^{\circ}$ semestres, pois nas demais os termos pesquisados são apenas citados sem maiores especificações da abordagem da temática no processo de ensino-aprendizagem.

$\mathrm{Na}$ disciplina de saúde mental lecionadas durante o sétimo semestre e no internato médico, o tema comparece no conteúdo programático e nos critérios de avaliação, conforme os trechos a seguir:

Demonstrar consciência da diversidade, respeitando as diferenças de natureza ambiental-ecológica, étnico-racial, de gêneros, faixas geracionais, classes sociais, religiões, necessidades especiais, orientações sexuais e outras. (Trecho do 
conteúdo programático da disciplina de saúde mental - $7^{\circ}$ semestre).

Esperamos que o interno desenvolva habilidades (interpessoais e de comunicação), que serão demonstradas na entrevista psiquiátrica, incluindo: [...] d. Quando necessário, usar de linguagem neutra para gênero, idade, raça, orientação sexual, cultura e religião. (Trecho dos critérios de avaliação do internato em saúde mental - $8^{\circ}$ semestre).

Apesar de formalmente presentes no plano de ensino da disciplina de saúde mental, os termos diversidade, gênero e orientação sexual estão inseridos como situações delicadas em que o/a discente deve "demonstrar consciência" e aprender a "usar uma linguagem neutra".

\subsection{Patologização da Transexualidade}

Ao analisar as narrativas dos/as alunos/as-participantes dos grupos focais, deparamo-nos com o memorar o processo de ensino-aprendizagem no qual a abordagem se aproxima à patologização do tema da transexualidade. "Eu não me lembro de um momento exato em que um professor chegou e abordou o tema, "isso num transexual", talvez na aula de saúde mental, citado nos transtornos de personalidade..." (Discente 2).

Embora a última atualização do DSM-V (Manual de Diagnóstico e Estatístico de Transtornos Mentais) não mais relacione o termo transexualidade à doença mental, os relatos dos grupos focais elucidam que a transexualidade tende a ser abordada na dicotomia cuja atribuição dos padrões comportamentais está associada ao órgão sexual, desconsiderando a construção social das expressões de gênero. Bento (2008) aponta que tanto a medicina quanto as ciências psi (psicologia, psiquiatria e psicanálise), ao invés de compreender a sexualidade como uma experiência identitária, podem, por vezes, considerar a transexualidade como uma "doença mental", criando, inclusive, procedimentos para legitimar o discurso patologizante.

Teve uma aula de humanidades médicas no primeiro período [semestre] em que foi levada uma psiquiatra para falar sobre transexualidade, na verdade foi gênero e sexualidade, mas enfim, e começou a se falar de transexualidade de uma forma totalmente errada. Era uma psiquiatra que começou a usar o DSM como base, dizendo um monte de coisa. Uma visão da transexualidade como um distúrbio mesmo. (Discente 1)

As narrativas situam que ainda há certa patologização da transexualidade no ensino médico. Bento e Pelúcio (2012) apontam a necessidade de interromper a produção de diagnóstico de transtorno mental em pessoas transexuais, uma vez que essa categoria nosológica tem efeitos múltiplos, tais como o aprisionamento das diferenças sexuais em meio à sociedade heteronormativa que desqualifica e patologiza as diferenças.

O processo de luta pela despatologização da população LGBTI+ reverbera na retirada do termo homossexualismo como doença mental no DSM-IV. A campanha Stop Trans Pathologization (pare a patologização das pessoas trans!) também teve visibilidade no enfrentamento aos ditames preconceituosos (Bento y Pelúcio, 2012). Entretanto, persistem expressões como "Disforia de Gênero" no DSM-V e "Transtornos da identidade sexual" no CID-10, manuais que se constituem como referência internacional na educação médica e nas demais áreas da saúde. 


\subsection{Contrastes do Processos de Ensino, Diretrizes Curriculares \& Formação Docente}

As situações de patologização da transexualidade retratadas nos grupos focais contrastam com o currículo formal de medicina. "Compreender aspectos bioéticos em questões étnico-raciais e questões de gênero. Bioética e direitos humanos, questões étnico-raciais e de gênero". (Trecho do conteúdo programático da disciplina Humanidades Médicas - $5^{\circ}$ semestre).

Embora as novas diretrizes curriculares proponham a inserção de uma disciplina voltada às questões humanitárias (humanidades médicas) no intuito de formar médicos/as com um olhar ampliado em relação à compreensão da diversidade e dos direitos humanos, ainda há dificuldade de romper com a abordagem patológica do tema na educação médica. Este fato parece estar relacionado, em parte, ao processo formativo dos/as docentes. Com a influência do modelo flexneriano para a padronização dos currículos das escolas médicas, no começo do século XX, houve o desenvolvimento de estratégias de ensino privilegiando alguns atributos, tais como: ensino por especialidades; concepção da doença como processo individual, natural e biológico; hospital como local por excelência para a implantação do binômio ensino-pesquisa (Pagliosa y Da Ros, 2008). Questionamentos quanto ao reflexo da formação docente comparecem nos grupos focais junto ao entendimento de que a introdução de novos temas e debates virá da sociedade, questão necessária para que ocorra uma abertura no meio acadêmico.

Será que os nossos professores sabem como lidar com isso? Será que eles sabem o manejo disso? Porque, querendo ou não, eles também já foram estudantes de medicina, quem sabe na faculdade deles nunca teve esse papo, nunca se abordou esse assunto... Eu fico pensando que às vezes a nossa educação com esse assunto não vai vir de professores, mas quem sabe vai vir de fora, com pessoas realmente transgêneros que nos ensinem como atender eles... O que é bem bizarro. (Discente 5)

\subsection{Sexualidade: ênfase nos processos biológicos e a estigmatização das diferenças}

$\mathrm{O}$ modelo flexneriano ainda influencia o curso de medicina ao privilegiar a segmentação clínica. Quando se discute sobre sexualidade humana, por exemplo, as questões biológicas são enfatizadas junto à correlação do assunto com infecções sexualmente transmissíveis, conforme comparece nas disciplinas de Ginecologia e Obstetrícia e Clínica Médica.

Unidade 2 - Desenvolvimento sexual. 1. Embriologia do Aparelho Reprodutor Feminino; 2. Fisiologia do Desenvolvimento Sexual da Infância e da Adolescência; 3. Fisiologia do Ciclo Menstrual; 4. Climatério e Menopausa; 5. Anticoncepção. (Trecho do conteúdo programático de Ginecologia e Obstetrícia - $4^{\circ}$ semestre).

Reconhecer as infecções sexualmente transmissíveis, além do HIV, mais prevalentes em nosso meio, com especial atenção às hepatites virais crônicas. Unidade 6 - Abordagem das doenças infecciosas mais prevalentes na prática médica (Trecho do conteúdo programático de Clínica Médica - $7^{\circ}$ semestre).

O ensino sobre sexualidade cuja ênfase recai sobre o funcionamento biológico e doenças sexualmente transmissíveis (DSTs) também foi relatada no meio científico brasileiro por Rufino, et al. (2013). Nos grupos focais as/os estudantes relatam que a 
sexualidade tende a ser abordada com maior ênfase às questões biológicas nas aulas, com conotação negativa das populações consideradas de "risco" às DSTs.

Eu não lembro exatamente qual foi a disciplina, mas eu tenho memória de que sempre que esse assunto (sexualidade) surgiu foi de forma negativa em relação à promiscuidade, DST e coisas do tipo, como se fosse uma população de risco (LGBT) (Discente 6)

A associação entre sexualidade e doenças remete à histórica construção social e científica vinculada às pessoas que vivem com HIV, o que evidencia o reducionismo no modo de abordar a temática da sexualidade. No começo da década de 1980, com a identificação dos primeiros casos de AIDS no Brasil, fez-se a correlação entre a síndrome e "populações de risco" caracterizadas como "promíscuas", levando à estigmatização. Embora os avanços em pesquisas relacionadas ao HIV/AIDS demonstrem que não há relação direta entre a síndrome e a população LGBTI+, a narrativa acima evidencia a continuidade desta associação no processo de ensino médico, com a perpetuação da ideia de "população de risco" atribuída às pessoas LGBTI+.

\subsection{Perspectiva Processual da Transexualidade: aprendizados com a sociedade}

Dentro de um processo histórico no qual os indivíduos são compreendidos como portadores de uma doença e vistos de maneira fragmentada pela medicina, amplificamse os obstáculos para acompanhar as pessoas transexuais na perspectiva da integralidade do cuidado. Torna-se primordial romper com o paradigma patologizante das abordagens reducionistas que se limitam a focar em intervenções sobre os corpos, como nos processos de hormonização, cirurgia de transgenitalização, entre outros, práticas nas quais se utilizam determinados domínios do saber sobre o outro. Nesse sentido, os discursos dos/as discentes de medicina estão relacionados a dois tipos de interpretações sobre o "corpo transexual": a relação corpo-mente fortemente influenciada pela caracterização biológica, e a processualidade de ser/estar transexual dentro de um contexto e história. Esta perspectiva está relacionada com as experiências extramuros das/os estudantes, ou seja, vivências e pesquisas não instituídas pelo curso de medicina. "Extraclasse, foi tudo interesse de aluno querendo trabalhar esse assunto, não tanto de uma docência querendo abordar isso com a gente". (Discente 5)

Em relação à compreensão da transexualidade como um processo, pode-se observar dois pontos de vista nas narrativas abaixo: o primeiro expressando um devir que se afirma na suspensão das diferenças e o segundo com a percepção para além do corpo, isto é, um atravessamento do indivíduo pelas interferências culturais e sociais:

Se tu for analisar a palavra transexual, tipo "trans", que é "passar" de uma sexualidade para outra, quem sabe às vezes não é nem uma categoria, e sim um processo de você estar passando de um gênero para o outro gênero. (Discente 5) Para uma mulher transexual, ela nasceu um homem perante a sociedade, mas para ela, ela é uma mulher independente da genitália. A questão da transexualidade, para mim, vai além da cirurgia, vai na questão de como a pessoa se percebe, de toda transição de vestuário, questão social, familiar, etc. (Discente 1)

\subsection{Relação Corpo-Mente na compreensão do Processo Transexualizador}

A compreensão da relação corpo e mente da pessoa transexual, fortemente influenciada pela caracterização da alteração biológica, transparece entre participantes da 


\section{Hachetetepé. Revista científica de Educación y Comunicación}

n²1, 56-69, 2020

pesquisa. A concepção da separação corpo-mente e a possibilidade da reparabilidade do órgão genital com a cirurgia pode ser identificada quando os/as acadêmicos/as narram:

Acho que a transexualidade é uma coisa que não fica só no físico. Tem muitos que não têm meios de chegar à cirurgia para mudar o corpo e acaba se mantendo num "trans mente". (Discente 2)

Eu fico nessa dúvida se é uma questão só mental ou se precisa ser mental e física junto. Eu acredito que seja mental e que a questão física vem como consequência. Acho que é mais mental, de a pessoa nascer e se ver em outro gênero (Discente 5)

Em 1997, o Conselho Federal de Medicina (CFM) autorizou os procedimentos transgenitalizadores. O processo transexualizador é promovido pelo Sistema Único de Saúde (SUS) com portarias que alertam à necessidade de cuidado com o uso de técnicas e recursos biotecnológicos desenvolvidos pela medicina na "construção de corpos", sobretudo para evitar danos e malefícios (Brasil, 2015). Nesta área do conhecimento a medicina detém poderes e saberes cerceados por valores éticos e morais. Por isso, tornase impreterível a construção de conhecimentos e do compromisso ético no ensino médico na assegurar os direitos das pessoas transexuais. "Eu não sei dados, mas acredito que a maioria tenha algum desejo de fazer a cirurgia de readequação" (Discente 1)

$\mathrm{O}$ desconhecido sobre o desejo da pessoa transexual no ensino da medicina pode ser visto como reflexo do distanciamento do debate, sobretudo, com as próprias pessoas transexuais. O saber médico ancorado em teorias psicobiológicas manifesta a avaliação de desajustes e alterações caraterizadas como estruturas orgânicas, levando à construção de parâmetros, quantificações, medições e localizações com a finalidade de explicações biológicas sobre a compreensão do indivíduo (Caponi, 2014).

\subsection{Violência e Discriminação da população LGBTI+}

Os/as acadêmicos/as de medicina refletem sobre a ordem regulatória em relação ao corpo orgânico e aos comportamentos sexuais, demonstrando a conscientização quanto aos desafios enfrentados pela população LGBTI+ na sociedade heteronormativa que desqualifica as diferenças situando-as como anormalidade. "Se você for ver, um homossexual ou um transexual, eles já nascem com um desafio de se entender numa sociedade em que a maioria das pessoas julga como não sendo normal.. ". (Discente 5)

A perspectiva preconceituosa que considera as pessoas LGBTI+ como anormais reside na procura pela parametrização do comportamento dos indivíduos na sociedade. Assim, à medida em que comportamentos sexuais diferem de distribuições de probabilidade para modelar fenômenos vistos como naturais, os desafios aumentam.

O Brasil é o país que mais mata transexuais no mundo (...) Uma das causas de morte é suicídio...e numa sociedade que não tem nenhum reconhecimento acaba, muitas vezes, sem emprego, vai para condição de rua. Tem muita trans que se torna profissional do sexo para tentar ter alguma forma de viver. (Discente 1)

Em 2018, o relatório de pessoas LGBTI+ mortas no Brasil, produzido pelo Grupo Gay da Bahia (GGB, 2018), identificou 420 lésbicas, gays, bissexuais e transexuais vítimas da homolesbotransfobia, 320 assassinatos e 100 suicídios. Entre 2011 e 2018, as denúncias de assassinato registradas pelo Disque 100, Transgender Europe e pelo GGB totalizam 4.422 mortos, o que equivale a 552 mortes por ano ou uma vítima de homofobia a cada 16 horas no Brasil. Conforme os dados do relatório citado, o Brasil foi campeão mundial de crimes contra as minorias sexuais. As estatísticas refletem a banalização da 
violência e sofrimento dessa população. Além da violência física identificada, existe, ainda, situações de violência moral enfrentadas pela população transexual.

Lembrei de outra situação na UBS ${ }^{2}$. As Agentes Comunitárias de Saúde tavam falando de uma mulher trans, dizendo que era um absurdo ela estar na UBS e que foi chamada pelo nome... Ela se identificava como mulher e foi chamada pelo nome masculino e não pelo nome social e tava fazendo um "piti". (Discente 6)

Ao mesmo tempo em que existe a necessidade de tornar visível a pessoa transexual na sociedade heteronormativa, essa exposição abre um campo de oportunidade para a manutenção de preconceitos por meio de constrangimentos como o citado na narrativa acima. O nome social, um artifício criado para combater preconceitos, acaba se tornando o motivo e o alvo da discriminação, apesar de ser garantido nos serviços de saúde enquanto direito dos/as usuários/as do SUS (Silva; Silva; Coelho; Maritiniano, 2017).

A abordagem do tema da transexualidade na educação médica ainda envolve certa invisibilidade e distanciamento do que se apresenta nas novas diretrizes curriculares do curso de medicina. Em estudo com estudantes de medicina de uma instituição pública de Santa Catarina, Moretti Pires (2017), refere que a comunicação de docentes para discentes transita pelo viés misógino e sexista.

\subsection{Processo de Ensino e Atravessamentos dos Valores Morais}

O discurso de notório saber sobre o que é relevante na formação médica baseada em seus cânones reverbera tanto na ênfase à dimensão biológica, ou mesmo patologizante da transexualidade, como nas resistências do corpo docente a ampliar a perspectiva psicossocial das necessidades de saúde no contexto em que o estudo foi realizado.

Eu imagino que querer que os professores falem sobre isso na faculdade agora... Professores que já estão trabalhando há muitos anos não vão querer botar um assunto que às vezes eles nem sabem. Eles não vão querer assumir que eles não sabem, vão querer dizer que não tem hora curricular para isso. (Discente 1)

O papel do/a docente de medicina frente às demandas das pessoas transexuais está atravessado pelo compromisso ético, porém, os enfrentamentos cotidianos na prática de ensino podem revelar dimensões vinculadas aos valores morais. $\mathrm{O}$ corpo docente da universidade participante do estudo é composto principalmente por médicos/as. Assuntos não recorrentes na prática clínica desses/as profissionais tendem a ficar em segundo plano, não sendo abordado nas aulas e práticas com os/as alunos/as, como é o caso do atendimento à população transexual. Quando a instituição de ensino não estabelece diretrizes que considerem a dimensão subjetiva e plural das experiências, essas questões serão abordadas dependendo da disponibilidade de cada docente em abordar tais aspectos. Não se trata de culpabilizar docentes, mas de evidenciar que os aspectos relacionados à sexualidade e expressões de gênero ainda são imbuídos de preconceitos e são situadas à margem na sociedade em que vivemos, o que se reflete, também, na formação médica.

Nos grupos focais foi consensual o papel relevante que a instituição de ensino desempenha e pode desempenhar no processo de aprendizagem das questões de gênero e sexualidade, enfatizando a importância de criar estratégias para descontruir preconceitos e qualificar a postura ética.

\footnotetext{
${ }^{2}$ Unidades Básicas de Saúde (UBS) são serviços de atenção primária à saúde localizados no bairro em que as pessoas vivem.
}

e-ISSN:2172-7910

Doi:10.25267/Hachetetepe.2020.i21.6

Universidad de Cádiz 
A gente entra na faculdade, cada um tem várias opiniões e vários preconceitos embutidos e acho que seria fundamental, de alguma forma, o curso desconstruir isso e te preparar, não para atender um transexual, mas para atender qualquer pessoa. A nossa profissão exige isso. (Discente 4)

A responsabilidade referida acima diz respeito à ética presente ao se considerar as diversidades do indivíduo, o que sintoniza com o objetivo das Diretrizes Curriculares Nacionais que orientam a formação médica (Brasil, 2014). "Acho que a gente tem que saber ouvir e conduzir. E pela universidade, o objetivo é que a gente se torne médico generalista para uma pessoa cis e para uma pessoa trans também. É só isso". (Discente 6)

A análise dos planos de ensino e dos debates suscitados nos grupos focais desta instituição demonstra que as temáticas relacionadas à transexualidade ainda são abordadas de modo incipiente com ênfase aos processos biológicos e patológicos, não satisfazendo as necessidades evidenciadas por acadêmicos/as de medicina quanto ao processo educativo relacionado às necessidades de saúde da população LGBTI+. Nos grupos focais foi evidenciada, também, a necessidade de respostas para possíveis demandas advindas do papel social do/a médico/a.

\section{ALGUMAS CONSIDERAÇÕES}

Estamos vivenciando um momento em que se tensionam mudanças em relação às diversas construções socioculturais heteronormativas baseadas em comportamentos misóginos, sexistas, taxativos e intransigentes. A luta pelos direitos humanos se soma ao processo de desconstrução dos preconceitos em relação à população LGBTI+. O serviço de saúde é porta de entrada para todas as pessoas, cada qual com sua singularidade e deve se alicerçar em preceitos éticos que sejam capazes de acolher a todos/as.

Por meio desta pesquisa, podemos constatar que mesmo com as novas Diretrizes Curriculares Nacionais de 2014 e a implementação dos temas relacionados à sexualidade e gênero nos planos de ensino, o processo de ensino-aprendizagem no curso de medicina da universidade-participante ainda é alicerçado em metodologias que enfatizam a perspectiva biomédica. Os/as discentes reconhecem o potencial que a universidade pode desempenhar para fomentar uma compreensão ampliada dos processos de saúde com reflexões críticas para desconstruir perspectivas pejorativas e preconceituosas.

Esse artigo organizou uma síntese das formulações de um pequeno grupo de estudantes do curso de medicina de uma universidade privada no sul do Brasil. Os resultados estão circunscritos a determinada realidade, podendo apresentar discrepâncias na mesma instituição e em outras regiões do país. Os grupos focais foram compostos por discentes que demonstraram interesse pelo tema, sendo unânime o anseio por aprofundar o conhecimento sobre a transexualidade. Se mesmo diante de um grupo interessado pelo tema ainda há diversas dúvidas, como há de ser a relação da maioria da comunidade acadêmica com a população LGBTI+? Assim, pode-se constatar a necessidade de uma educação médica baseada no compromisso ético-político-social para acolher as pessoas na diversidade de questões que subjetivam seus modos de viver e existir no mundo.

\section{REFERÊNCIAS BIBLIOGRÁFICAS}

Bardin L. (2011). Análise de Conteúdo. São Paulo: Edições 70.

Bento B. (2008). O que é Transexualidade. São Paulo: Ed. Brasiliense. 
Bento B., y Pelucio L. (2012). Despatologização do gênero: a politização das identidades abjetas. Revista Estudos Feministas, 20(2), 559-568. https://doi.org/10.1590/S0104-026X2012000200017

Brasil (2014). Ministério da Educação. Conselho Nacional de Educação. Câmara de Educação Superior. Resolução No. 3 de 20 de junho de 2014. Institui diretrizes curriculares nacionais do curso de graduação em Medicina e dá outras providências. Diário Oficial da União, Brasília, 23 jun. 2014; Seção 1, p. 8-11.

Brasil (2015). Ministério da Saúde. Secretaria de Gestão Estratégica e Participativa. Departamento de Apoio à Gestão Participativa. Transexualidade e travestilidade na saúde. Ministério da Saúde. Brasília.

Campos F.E. y Belisário S.A. (2001). O Programa de Saúde da Família e os desafios para a formação profissional e a educação continuada. Interface - Comunicação, Saúde e Educação, 5(9), 133-142. https://doi.org/10.1590/S1414-32832001000200009

Caponi S. (2014). Post Scriptum. Georges Canguilhem: do corpo subjetivo à localização cerebral. En S. Caponi Loucos e degenerados: uma genealogia da psiquiatria ampliada. (pp.185-202). Rio de Janeiro: Fiocruz.

GGB. (2018). Grupo Gay da Bahia. Relatório 2018: pessoas LGBTs mortas no Brasil. Disponible em: https://homofobiamata.files.wordpress.com/2019/01/relatorio2018-1.pdf

Leite A.S. y Santos C. (2016). Cartografias trans: mapas sobre a apropriação médica das transexualidades. Clínica \& Cultura. 5(1), 50-64. Disponible em: https://seer.ufs.br/index.php/clinicaecultura/article/view/4619

Liang, JJ., Gardner, IH, Walker, JA. y Safer, JD. (2017). Observed Deficiencies in medical student knowledge of transgender and intersex health. Endocrine Practice. 23(8), 897-906.

Ling-Fang, C. y Hsing-Chen, Y. (2015). Learning about gender on campus: an analysis of the hidden curriculum for medical students. Medical Education. 49(3), 321-331.

https://doi.org/10.1111/medu.12628

Minayo M.C.S. (2014). O desafio do conhecimento. São Paulo: Hucitec.

Moretti Pires R.O. (2017). Domesticando corpos, construindo médicos: das relações de gênero a uma sociologia das profissões. Santa Catarina. Dissertação de Mestrado. Universidade Federal de Santa Catarina. Disponible em: https://repositorio.ufsc.br/handle/123456789/176795

Obedin-Maliver, J., Goldsmith, E.S., Stewart, L., White, W., Tran, E., Brenman, S., Wells, M., Fetterman, D.M., Garcia, G. y Lunn, M.R.(2011). Lesbian, gay, bisexual, and transgender-related content in undergraduate medical education. Jama, 306(9), 971-977.

ONU. (2012). Organização das Nações Unidas. Born free and equal: sexual orientation and gender identity in International Human Rights Law. Genebra: UNHR. Disponible em: https://www.ohchr.org/Documents/Publications/ BornFreeAndEqualLowRes.pdf

Pagliosa F.L. y Da Ros, M.A. (2008) O relatório Flexner: para o bem e para o mal. Revista Brasileira de Educação Médica, 32(4), 492-499. https://doi.org/10.1590/S010055022008000400012

Ribeiro M.M.F. y Amaral, C.F.S. (2008) Medicina centrada no paciente e ensino médico: a importância do cuidado com a pessoa e o poder médico. Revista Brasileira de 
Educação Médica, 32(1), 90-97. $\quad$ http://doi.org/10.1590/S010055022008000100012

Ristow AM. (2007.) A formação humanística do médico na sociedade do século XXI: uma análise curricular. Dissertação de Mestrado. Universidade Federal do Paraná. Disponible em: https://acervodigital.ufpr.br/handle/1884/13312

Rondahl, G. (2009). Students inadequate knowledge about lesbian, gay, bisexual and transgender persons. International Journal of Nursing Education Scholarship. 6(1), 1-15.

Rufino AC., Madeiro A.P. y Girão M.J.B.C. (2013). O Ensino da Sexualidade nos Cursos Médicos: a percepção de estudantes do Piauí. Revista Brasileira de Educação Médica, 37(2), 178-185.

Sanchez, N., Rabatin, J., Sanchez, J.P., Hubbard, S, y Kalet, A. (2006). Medical students' ability to care for lesbian, gay, bisexual, and transgendered patients. Family Medicine, 38(1), 21-27.

Santos, TZ y Cruz, TM. (2014). Os modos da transexualidade: entrelaçamentos de gênero e orientação sexual. Poiésis, 8(13), 141-155. Disponible em: http://www.portaldeperiodicos.unisul.br/index.php/Poiesis/article/view/2253

Silva, L.K.M., Silva, A., Coelho, A.A. y Maritiniano C.S. (2017). Uso do nome social no Sistema Único de Saúde: elementos para o debate sobre a assistência prestada a travestis e transexuais. Physis Revista de Saúde Coletiva, 27(3), 835-846. http://doi.org/10.1590/s0103-73312017000300023

Tamas, R.L., Miller, K.H., Martin, L.J., y Greenberg, R.B. (2010). Addressing patient sexual orientation in the undergraduate medical education curriculum. Academic Psychiatry, 34(5), 342-345. 